\title{
EDITORIAL
}

\section{CTAD INTERNATIONAL RESEARCH CONFERENCE: CLINICAL TRIALS IN ALZHEIMER'S DISEASE}

We are very pleased to offer to the readers of The Journal of Nutrition, Health \& Aging this collection of articles published in the wake of the 1 st Conference on Clinical trials in Alzheimer's Disease (AD), which took place in Montpellier, France, September 17-19th 2008. The wide range of topics in this supplement is representative of the wealth of information that was exchanged in the Conference, which took place after notable failures in Phase III of drugs acting on different aspects of amyloid metabolism. A fresh look at animal models and phase II/III methodology was urgently needed. One particular feature of this Conference and this supplement is awareness that outcomes used in randomized clinical trials must be translated into clinical effectiveness for users and payers. Furthermore investigators are well aware of the need to treat $A D$ in its pre-dementia stages in order to prove disease modification. We now need to prove it using the best possible designs and outcomes.

S. Gauthier

McGill Center for Studies in Aging, Montréal, Canada
We are pleased to publish in this issue of the journal a selection of publications (1-13) presented at the CTAD meeting in Montpellier. The CTAD is an International Conference on Clinical Trials in Alzheimer's Disease. New drugs are presently in development with some potential disease modifying effects : gamma secretase and beta secretase inhibitors, alpha secretase modulators, passive and active immunotherapy, ....it is now time to work all together on the best study design for these trials. Moreover, validation and development of biomarkers, neuro-imaging are a hot topics for clinical trials. All these aspects were presented at the the CTAD meeting in Montpellier, France. The 2009 CTAD International Research Conference will be organized on October 28, 29, 30th 2009 in Las Vegas, USA in conjonction with the opening of the Lou Ravo Brain Institute. The deadline for abstract submissions in June $15^{\text {th }}, 2009$ on http//www.ctad.fr. The 2010 CTAD conference will be hosted in Toulouse, France. The aims of these conferences are to bring together the principal investigator of major trials presently in process or development in the field of Alzheimer's Disease.

\section{J. Touchon', B.Vellas ${ }^{2}$, Z. Katchaturian ${ }^{3}$ \\ 1. Department of neu rolgy, CMRR, CHU Montpellier, France; 2. Gérontopôle, CMRR, CHU Toulouse, France; 3. Lou Ravo Brain Institute, Las Vegas, USA}

\section{References}

1. K. Blennow, G. De Meyer, O. Hansson, L. Minthon, A. Wallin, H. Zetterberg, P Lewczuk, H. Vanderstichele, E. Vanmechelen, J. Kornhuber, J. Wiltfang and KNDstudy group. Evolution of $\mathrm{A} \beta 42$ and $\mathrm{A} \beta 40$ Levels and Aß42/Aß40 Ratio in Plasma during Progression of Alzheimer's Disease: A Multicenter Assessment. J Nutr Health Aging. 2009; 13(3):205-208
2. G.B. Frisoni, A. Delacourte. Neuroimaging Outcomes in Clinical Trials in Alzheimer's Disease. J Nutr Health Aging. 2009; 13(3):209-212

3. R. Ramírez-Lorca, M. Boada, M.E. Sáez, I. Hernández, A. Mauleón, M. RosendeRoca, P. Martínez-Lage, M. Gutiérrez, L.M. Real, J. López-Arrieta, J. Gayán, C. Antúnez, A. González-Pérez, L. Tárraga, A. Ruiz. GAB2 Gene Does Not Modify the Risk of Alzheimer's Disease in Spanish APOE 4 Carriers. J Nutr Health Aging. 2009; 13(3):214-219

4. D.R. Lachno, H. Vanderstichele, G. De Groote, V. Kostanjevecki, G. De Meyer, E.R. Siemers, M.B. Willey, J.S. Bourdage, R.J. Konrad, R.A. Dean. The Influence of Matrix Type, Diurnal Rhythm and Sample Collection and Processing on the Measurement of Plasma ß-Amyloid Isoforms Using the Inno-Bia Plasma A $\beta$ Forms Multiplex Assay. J Nutr Health Aging. 2009; 13(3):220-225

5. M. Berwig, H. Leicht, H.J. Gertz. Critical Evaluation of Self-Rated Quality of Life in Mild Cognitive Impairment and Alzheimer's Disease - Further Evidence for the Impact of Anosognosia and Global Cognitive Impairment. J Nutr Health Aging. 2009; 13(3):226-230

6. J.A.H.R. Claassen, A.H.E.A. van Beek, M.G.M. Olde-Rikkert. Short Review: Acetylcholinesterase-Inhibitors in Alzheimer's Disease Have Opposing Effects on Blood Pressure and Cerebral Perfusion. J Nutr Health Aging. 2009; 13(3):231-233

7. P. Szaniszlo, P. German, G. Hajas, D.N. Saenz, M. Kruzel, I. Boldogh (USA). New Insights into Clinical Trial for Colostrinin ${ }^{\mathrm{TM}}$ in Alzheimer's Disease. J Nutr Health Aging. 2009; 13(3):235-241

8. E.J. Meeuwsen, R.J.F. Melis, E.M. Adang, G.A. Golüke-Willemse, P.F. Krabbe, B.J. de Leest, F.H.J.M. van Raak, C.J.M. Schölzel-Dorenbos, M.C. Visser, C.A. Wolfs, S. Vliek, M.G.M. Olde Rikkert. Cost-Effectiveness of Plost-Diagnosis Treatment in Dementia Coordinated by Multidisciplinary Memory Clinics in Comparison to Treatment Coordinated by General Practioners: An Example of a Pragmatic Trial. J Nutr Health Aging. 2009; 13(3):242-248

9. R.E. Tractenberg. Analytic Methods for Factors, Dimensions and Endpoints in Clinical Trials for Alzheimer's Disease. J Nutr Health Aging. 2009; 13(3):249-255

10. C.W. Zhu, C. Leibman, R. Townsend, T. McLaughlin, N. Scarmeas, M. Albert, J. Brandt, D. Blacker, M. Sano, Y. Stern. Bridging from Clinical Endpoints to Estimates of Treatment Value for External Decision Makers. J Nutr Health Aging. 2009; 13(3):256-259

11. E. Leone, A. Deudon, N. Maubourguet, X. Gervais, P.H. Robert. Methodological Issues in the Non Pharmacological Treatment of BPSD in Nursing Home - The TNM Study -. J Nutr Health Aging. 2009; 13(3):260-263

12. A. Schneeberger, M. Mandler, O. Otava, W. Zauner, F. Mattner, W. Schmidt Development of Affitope Vaccines for Alzheimer's Disease (AD) - From Concept to Clinical Testing. J Nutr Health Aging. 2009; 13(3):264-267

13. R.H. Pietrzak, P. Maruff, P.J. Snyder. Methodological Improvements in Quantifying Cognitive Change in Clinical Trials: An Example with Single-Dose Administration of Donepezil. J Nutr Health Aging. 2009; 13(3):268-273 